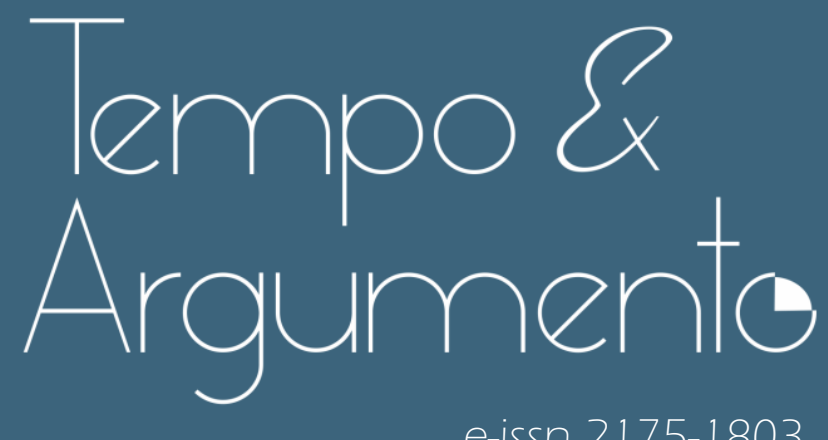

e-issn 2175-1803

Teoria(s) feminista(s) e história(s) do tempo presente: interseccionalidade, subalternidade e decolonialidade

- Christelle Taraud

Professora da NYU Paris \& Centro de História do século XIX (Paris 1 e 4).

Paris - FRANÇA

christelle.taraud@wanadoo.fr

Artigo original: Théorie(s) féministe(s) et histoire/s) du temps présent:

intersectionnalité, subalternité et décolonialité

Tradução: Christian Abes

Revisão: Silvia Maria Fávero Arend e Fernando Coelho 


\title{
Teoria(s) feminista(s) e história(s) do tempo presente: interseccionalidade, subalternidade e decolonialidade
}

\begin{abstract}
Resumo
O objetivo deste artigo é (re)pensar a(s) história(s) do tempo presente à luz das teorias feministas que, através dos conceitos de interseccionalidade, subalternidade e decolonialidade, oferecem uma visão ao mesmo tempo fecunda e renovada. No cerne da abordagem, a ideia de contornar/submergir as visões hegemônicas, totalizantes e / ou dominantes, para aclarar a contrário a pluralidade de existência(s)/experiência(s) e modalidades práticas, teóricas e simbólicas de sua(s) múltiplas expressão(ões) por meio de pluri-interpretação(ões)/reflexão(ões) pensadas de maneira horizontal (ao nível do solo, pode-se dizer) e não hierárquica(s). Aqui um multifocal de segmentos polimórficos, traços difusos e narrativas fragmentárias emergiria, formando corpo-unidade não por categorizaçãohierarquização fixista, mas por justaposição-coabitação lábil, propondo uma visão verdadeiramente humana e universal.
\end{abstract}

Palavras-chave: teorias feministas; interseccionalidade; subalternidade; decolonialidade; feminicídio/ecocídio.

\section{Feminist theory(s) and history(s) of the present time: intersectionality, subalternity and decoloniality}

\begin{abstract}
The aim of this article is to (re)think the history(s) of the present time in the light of the feminist theories that, through the concepts of intersectionality, subalternity and decoloniality, offer a view that is at the same time fruitful and renewed. At the heart of the approach, the idea of detouring/submerging the hegemonic, totalizing and / or dominant views, in order to clarify, a contrario, the plurality of existence(s)/experience(s) and practical, theoretical and symbolic modalities of their multiple expression(s) through pluri-interpretation(s)/reflection(s) thought horizontally (at ground level, it can be said) and not hierarchical. Here a multifocal view of polymorphic segments, diffuse traits and fragmentary narratives would emerge, forming a body-unity not by a fixing categorization-hierarchization, but by changeable juxtaposition-cohabitation, proposing a truly human and universal view.
\end{abstract}

Keywords: feminist theories; intersectionality; subalternity; decoloniality; feminicide/ecocide. 
Desde seu nascimento no século XIX1, O(s) feminismo(s) - tanto como ação/ões quanto pensamento(s) - foram alvos, quase em toda parte, de ataques violentos, dando assim surgimento, no mesmo impulso, a antifeminismos estruturais e persistentes, os quais cabe questionar através de perspectivas contemporâneas que buscam investigar profundamente as nossas sociedades atuais e que são, antes de tudo, objetos de interesse da(s) história(s) do tempo presente.

Nascidos, pelo menos na Europa ocidental², numa época de fortes restruturações políticas, econômicas e sociais - êxodo rural intenso, industrialização e urbanização crescentes, capitalismo industrial em vias de mundialização e suas consequências, colonização planetária agressiva, predadora, desestruturante e des-conhecedora... - o(s) feminismo(s), no entanto, nunca tiveram uma só voz e nunca tiveram uma cara só (TARAUD, 2005). Esta evidência da pluralidade dos feminismos - que precisamos colocar no plural a contrario do uso geral que faz deles um bloco homogêneo associado à cor da pele e à classe social (resumindo, o "feminismo branco e burguês") - levou, desde sua origem, a ambivalências, tensões, fortes rupturas, assim como a alianças conjunturais ou perenes. Pois, teoria(s) política(s) local(is) e global(is) ao mesmo tempo, os feminismos foram com certeza sensíveis à lógica interseccional e isto muito antes que o conceito fosse teorizado, em 1989, pela jurista feminista Kimberlé Crenshaw (CRENSHAW, 1989).

Aliás, esta interseccionalidade dos feminismos contemporâneos é muito bem traduzida pelo fato de que, já no século XIX, existe um "feminismo operário e/ou revolucionário" e um "feminismo burguês e/ou reformista": duas tendências complexas do(s) feminismo(s) que são entretanto a perfeita representação da sociedade de classes que surge então na Europa ocidental. De fato, não

\footnotetext{
Claro que existiam pensadoras da igualdade dos sexos e grupos « proto-feministas » muito antes do século XIX como comprovam, no caso da França, as obras de Christine de Pisan, de Marie de Gournay, de Madeleine de Scudéry ou, ainda, de Olympe de Gouges, para citar apenas as mais conhecidas...

2 Observemos, desde já, o nascimento no mesmo período de feminismos orientais (turco, egípcio, tunisino, indiano...) muitas vezes ausente das narrativas, elitistas ou populares, sobre a gênese dos movimentos feministas em escala planetária. Observemos também que estes primeiros feminismos orientais foram em geral muito impregnados das ideias provenientes da « modernidade » ocidental, fato que não diminui sua legitimidade, nem sua importância e nem sua relevância...
} 
Teoria(s) feminista(s) e história(s) do tempo presente: interseccionalidade, subalternidade e decolonialidade

Christelle Taraud

esqueçamos que a luta de classes, que foi tão importante na história europeia do século XIX e particularmente na história da França (refiro-me aqui especialmente às revoluções proletárias abortadas de 1848 e de 1871), foi feita com revolucionárias feministas (Louise Michel, Alexandra Kollontaï, Rosa Luxemburgo, tomando apenas três exemplos esclarecedores em três diferentes países) que tinham clara consciência não somente das relações de dominação entre patriarcado e capitalismo, mas também daquilo que unia, poderíamos dizer de modo ontológico, racismo de classe e racismo biológico, quer este último seja etnicizado e/ou culturalizado (TARAUD, 2009) ${ }^{3}$.

Nos anos 1970, enquanto os movimentos de libertação das mulheres trouxeram de volta a questão das discriminações sofridas pelas mulheres e pelas "minorias sexuais" 4 - sabemos a importância das lésbicas políticas nestes mesmos movimentos assim como o seu papel fundamental no âmbito das teorias feministas emergentes, como é o caso, por exemplo, de Adrienne Rich (RICH, 1980) - em espaços de destaque tanto nacionais quanto internacionais, o tema central do patriarcado e da heteronormatividade (KATZ, 1990, 1995; TIN, 2009) permanece ainda vinculado a questões maiores como classe e "raça". Através do ressurgimento de um feminismo radical ${ }^{5}$, do qual várias pensadoras como Christine Delphy e Monique Wittig são, na França, as herdeiras diretas, as questões sexuais e identitárias se tornam também elementos essenciais de

\footnotetext{
${ }^{3}$ Ver Louise Michel e a revolta Canaca (1878). Christelle Taraud, «Les bagnes de l'Empire au féminin: ou comment déporter les opposantes politiques de la métropole dans les colonies françaises au XIX siècle », in Anne Morelli (dir.), "Femmes exilées politiques », Sextant, $n^{\circ} 26$, Bruxelles, Presses de l'Université Libre de Bruxelles, 2009, p.17-25.

${ }^{4}$ A noção de "minoria sexual" é problemática para mim, pois mantém a ideia de que estas práticas sexuais, às vezes atreladas a identidades de gênero, seriam "periféricas" ou "marginais" aos olhos da grande centralidade heteronormativa. Na falta de algo melhor, uso então a expressão entre aspas.

5 O feminismo radical - no intervalo entre o feminismo burguês (em parte motivado pelos movimentos reformistas de filiação cristã) e o feminismo operário e/ou revolucionário (muito impregnado do marxismo, do socialismo e, em seguida, do comunismo) - sempre foi minoritário e, isso, desde seu nascimento no fim do século XIX e no começo do século XX. É alavancado por personalidades muito atípicas oriundas de correntes de pensamento singulares - livre pensamento, anarco-feminismo, eco-feminismo, feminismo espiritualista... - e é centrado em questões que poderíamos definir como mais "individuais" (particularmente questões sexuais e identitárias) em relação às grandes questões "coletivas” das outras tendências. Sendo assim, entendemos por que este feminismo radical, encarnado na França, por exemplo, na figura de uma pensadora como Madeleine Pelletier, esteve no centro do pensamento feminista dos anos 1970 na Europa ocidental. As relações entre pensamento e ação de figuras como Madeleine Pelleteir e Monique Wittig ficam assim mais do que claras...
} 
Teoria(s) feminista(s) e história(s) do tempo presente: interseccionalidade, subalternidade e decolonialidade

Christelle Taraud

contestação do pensamento dominante e das normas que o regem. Estes movimentos dos anos 1970 são, para a questão que nos interessa hoje, fundamentais porque vão permitir, através da criação dos primeiros departamentos de Women Studies e, em seguida, de Gender Studies e de Queer Studies, uma reflexão profunda e profícua acerca das relações de dominação e dos mecanismos de poder que operam em nossas sociedades atuais.

Relações de dominação e mecanismos de poder que serão aqui objetos de uma análise em três pontos: Saberes hétero/saberes situados; Subalternidade(s) e racismo de classe; Decolonialidade(s) mundializada(s)...

\section{Saberes Hétero/saberes situados}

Como enfatizado pela antropóloga feminista Rita Laura Segato em um artigo intitulado "A Manifesto in Four Themes":

Na América latina, "a ideologia de gênero" apareceu recentemente como uma categoria a serviço de acusações. No Brasil, houve numerosas propostas legislativas encaminhadas por um movimento chamado Programa Escola sem Partido, ou Programa por uma Escola Não-partidária. Uma destas propostas de leis proibiria "a aplicação de postulados da teoria ou 'ideologia de gênero'" na educação, assim como "qualquer prática capaz de comprometer, precipitar ou direcionar o natural amadurecimento e desenvolvimento da sua personalidade em harmonia com a respectiva identidade biológica de sexo. (Segato, 2018, p. 199)

Este fato nos remete, do outro lado do Atlântico, a outra ofensiva orquestrada e lançada ao mesmo tempo contra os estudos de gênero e os estudos decoloniais na França, o que vem ocorrendo há aproximadamente vinte $\operatorname{anos}^{6}$. A última amostra desta longa polêmica ocorreu nas afirmações dadas à

\footnotetext{
Como reportado pelo jornal Le Monde num artigo de 17 de fevereiro de 2021: "Num primeiro momento, este comentário tinha provocado 'espanto' na Conferência dos Presidentes de Universidades. Na terça-feira [16 de fevereiro de 2021], estes tinham denunciado num comunicado as 'representações caricaturais' e 'argúcias de botequim' da Sra. Vidal. Na quartafeira, o próprio CNRS adotou um tom crítico condenando 'as tentativas de deslegitimação de diferentes campos de pesquisa'”. Acessar: http://www.cpu.fr/actualite/islamo-gauchismestopper-la-confusion-et-les-polemiques-steriles/;

https://www.lemonde.fr/education/article/2021/02/17/islamo-gauchisme-le-cnrs-condamne-lusage-d-un-terme-qui-ne-correspond-a-aucune-realite-scientifique-frederique-vidal-souspression_6070331_1473685.html
} 
Teoria(s) feminista(s) e história(s) do tempo presente: interseccionalidade, subalternidade e decolonialidade

Christelle Taraud

CNews em 14 de fevereiro $2021^{7}$ pela ministra do Ensino Superior e da Pesquisa, Frédérique Vidal, que encarregou o CNRS de fazer um "estudo científico" sobre o "islamo-esquerdismo" 8 - termo inventado, a propósito, nos meios da extrema direita europeia - nas universidades francesas buscando diferenciar "o que decorre da pesquisa acadêmica e o que decorre do militantismo e da opinião". Em ambos os casos, destacamos o caráter "partidário" - ou seja, não científico aos olhos de seus detratores(as) - dos saberes produzidos por aqueles e aquelas que, tanto no Brasil como na França, utilizam, entre outras teorias e ferramentas conceituais, o "gênero" e a "decolonialidade" nas suas análises científicas e políticas.

Quando publica, em 1980, “O pensamento hétero”, a filósofa e teórica do feminismo Monique Wittig faz, no entanto, uma bela demonstração da inanidade deste tipo de polêmica que busca opor, de modo caricatural e antagônico, pesquisa e ativismo, defendendo, pelo contrário, uma conscientização massiva e informada sobre esta questão, central para nosso argumento, da ortodoxia dos saberes-poderes (WITTIG, 1980). Partindo de uma crítica de três disciplinas essenciais das Ciências Humanas - a Semiologia (Barthes), a Antropologia (LevyStrauss) e a Psicanálise (Lacan) - ela demonstra que toda "ciência" é ideologia já que tanto em sua gênese ${ }^{9}$ quanto em sua produção de discurso (e, por conseguinte, na difusão desta através de (meta-)linguagens e de línguas da dominação), ela é o produto de uma casta/classe hegemônica que, universalizando seus interesses privados, impôs, pela força e/ou pelo "consentimento" 10, de acordo com os lugares e as épocas, “interpretações totalizantes" do nosso mundo comum. Nesta dinâmica - na qual o que está em

\footnotetext{
Afirmações reiteradas na Assembleia nacional na terça-feira 16 de fevereiro de 2021.

8 O "Islamo-esquerdismo" é um neologismo indicando a suposta proximidade - até mesmo o conluio - entre ideologias e partidos de extrema esquerda e os meios islamistas. Esta "teoria" tornaria os islamistas, inclusive os jihadistas, em nova vanguarda de um proletariado mundial dominado com o qual alianças seriam então possíveis no âmbito da re-internacionalização da luta de classes numa lógica, evidentemente, anticapitalista e anti-imperialista. Sobre esta questão, vale consultar, por exemplo, a análise feita por Chris Harman, dirigente do Partido Socialista dos trabalhadores no Reino-Unido, em seu artigo « The Prophet and the Proletariat », in International Socialism Journal, vol. 2, issue 64, Autumn 1994 https://www.marxists.org/archive/harman/1994/xx/islam.htm

9 Evidentemente, seria necessário desenvolver aqui uma reflexão formada pela história destas "ciências", o que seria impossível no âmbito deste artigo.

10 A questão do "consentimento" dos/as dominados/as em relação à sua própria dominação é muito complexa e não pode ser desenvolvida aqui.
} 
jogo é nada menos do que a construção de uma "verdade universal-natural", logo "a-histórica" e "a-política", que seria imposta a todos e todas de modo indiferenciado - os saberes-poderes, ao normatizar indivíduos e sociedades, obrigaram todos/as os/as dominados/as a fazer corpo (em todos os sentidos do termo) com os discursos da dominação que os oprimem, os exploram, os estigmatizam e os marginalizam. Deste modo, como bem enfatizado por Monique Wittig:

o poder que a ciência ou a teoria tem de agir materialmente sobre nossas pessoas não tem nada de abstrato mesmo se abstrato parece o discurso que elas produzem. Ele é uma das formas de dominação, a sua expressão, diz Marx. Aliás, eu diria que é um de seus exercícios. Todos os oprimidos o conhecem e se depararam com este poder. É aquele que diz: você não tem direto à fala porque seu discurso não é científico, não é teórico, você está errado no nível da análise, você confunde discurso e realidade, você sustenta um discurso ingênuo, você conhece mal tal ou tal ciência, você não diz o que você diz. (WITTIG, 1980, p. 49).

Definindo aqui o "pensamento hétero" - formado de "conceitos primitivos tais como 'mulher', 'homem', 'diferença', 'hierarquização', 'desigualdade', que interagem num conglomerado de todo tipo de disciplinas, teorias, correntes no objetivo de estabelecer a ideia da 'naturalidade' obrigatória da diferença dos sexos, da binariedade do gênero e da relação heterossexual procriadora" - como uma matriz totalizante, Monique Wittig nos lembra o quanto aquilo que acreditamos ser "saberes objetivos" desenvolvidos dentro de "ciências apresentadas como neutras" não passa de mera ilusão.

A este primeiro nível de questionamento, é preciso, desde já, acrescentar outro que diz respeito não só aos discursos em si, mas aos seus produtores: palavra flexionada por mim no masculino propositalmente... Pois, como fazer aqui um debate sobre a apropriação histórica do domínio do pensamento - e logo daquele dos saberes e das ciências - por uma casta/classe de homens que não só excluiu as mulheres da produção deste mesmo pensamento (ao mesmo tempo que o deslegitimou sistematicamente quando este eclodia mesmo assim, apesar da violência, da censura e da invisibilização, sem contar a monopolização de seu trabalho - efeito Mathilda (ROSSITER, 2003) - bem como os assassinatos de "femmes savantes" ["mulheres sabidas"] que pontuam a história) mas tentou, 
através de um "feminicídio historiográfico" em constante operação, de erradicálas, pura e simplesmente, da história humana... Uma história humana produzida por homens, para homens, sobre homens, onde as mulheres poderiam apenas ter um lugar residual e marginal enquanto "segundo sexo", submisso e dominado, tal como é lembrado por simone de Beauvoir em seu livro homônimo...

A propósito, vale observar que se as teorias feministas são tão demonizadas hoje, isto deve-se também ao fato de que, pela primeira vez na história da humanidade, elas são justamente produzidas por mulheres dentro de instituições - as universidades patriarcal-capitalistas - que fizeram de tudo para excluí-las e continuam a tratá-las como migalhas; e no contexto das disciplinas (particularmente a Filosofia e a História, ciências antigas pensadas historicamente como "masculinas") que estas mesmas teorias tendem a infiltrar/corromper/prejudicar pela sua escolha epistemológica do inter(inclusive da inter-disciplinaridade): ou seja, do entre-lugar, do não-binário, do não-normativo, do não-conforme, do marginal, do subalterno, do Outro... Pois, a contrario deste mito ainda sustentado da "neutralidade" e da "objetividade" científicas - do qual entendemos que ele era apenas uma fachada para mascarar o confisco histórico dos saberes-poderes por uma minoria de homens - as teorias feministas se encaminharam na via da "subjetividade crítica" que leva necessariamente a produzir "saberes situados" muitas vezes a partir de "objetos errados" e graças a "fontes menosprezadas e/ou deslegitimadas" (fontes orais, arquivos do íntimo, documentos provenientes da cultura popular...) reconhecendo, desta forma, que as ciências, que são também "organismos humanos/vivos", não podiam de maneira alguma ser desconectadas dos indivíduos e das sociedades que as produzem.

\section{Subalternidade(s) e racismo de classe}

O questionamento dos saberes-poderes e de seus produtores "naturais" - homens geralmente oriundos das elites brancas e/ou ricas dos mundos ocidentais" ${ }^{11}$ - pelos/as dominados/as eles-mesmos (mulheres, grupos LGBTI+,

\footnotetext{
${ }^{11}$ Aqui, a noção de ocidente é pensada num sentido geopolítico hipertrofiado visto que permite reunir países europeus, americanos (como os Estados Unidos e o Canadá), asiáticos (como o
} 
Teoria(s) feminista(s) e história(s) do tempo presente: interseccionalidade, subalternidade e decolonialidade

Christelle Taraud

minorias racializadas, povos originários e primeiras nações...) levou ao reconhecimento de um outro hiatus que as teorias feministas tentaram articular. Grandes produtores de normas e grandes ordenadores da normalidade, os saberes-poderes se concentraram essencialmente sobre os dominantes considerando tudo aquilo que não pertencia ao seu "cenáculo" como "subalterno", inclusive, claro, no contexto científico (o que nos leva de volta à questão dos "objetos errados", mencionados anteriormente, tratados então com o intuito de reconfortar a ortodoxia político-científica como demonstram os trabalhos desenvolvidos, no século XIX, sobre os "anormais", em especial os homossexuais e as prostitutas ${ }^{12}$ ). Aliás, as "classes subalternas" (tais como definidas por Antonio Gramsci), seja pela revolta contra a ordem imposta, seja pelo consentimento a contragosto, sempre foram consideradas classes secundárias: exploráveis em tempos de paz, sacrificáveis em tempos de guerra. Isto sustentou - e sustenta ainda - um racismo de classe que foi constitutivo da "modernidade" ocidental, como demonstra o tríptico fundador da ideologia burguesa e capitalista do século XIX, "classes trabalhadoras, classes perigosas, classes perversas”. Dentro deste sistema hegemônico total - político, econômico, social, racial, cultural, midiático, intelectual, linguístico... - pensado e ativado pelas classes de posse/de saber, as mulheres pobres pagaram o preço mais alto, mesmo que todas as mulheres tenham sido afetadas por meio de diferentes dispositivos de controle e de coerção: bicategorização ("mulheres-ventre honestas", "mulheres-sexo desonestas"), moral dupla e obrigação a uma feminilidade hétero ancorada na reprodução-maternidade no contexto exclusivo da família patriarcal-capitalista e limitada, tanto quanto possível, ao espaço carcerário-doméstico..

Japão, Singapura e Taiwan), do Oriente Médio (como Israel), da Oceania (como Austrália e a Nova Zelândia)... para além de sua colocação geográfica no globo. Observemos que cada país, constituindo em si uma "centralidade", tem então uma variação no seu "Oriente" e seu "Ocidente".

12 Como exemplo, podemos citar a obra monumental - apresentada como o primeiro estudo científico (fruto de oito anos de pesquisa de arquivos e de "campo") sobre a prostituição em Paris - do doutor Alexandre Parent-Duchatelet, que dará origem ao sistema "moderno" de regulamentação da prostituição na escala francesa, europeia e até mesmo mundial ao longo do século XIX e no início do século XX. Alexandre Parent-Duchatelet, De la prostitution dans la ville de Paris considérée sous le rapport de l'hygiène publique, de la morale et de l'administration, Paris, L. Baillière \& Fils, 1836. 
Teoria(s) feminista(s) e história(s) do tempo presente: interseccionalidade, subalternidade e decolonialidade

Dentro mesmo das "classes subalternas", a questão das mulheres era objeto de grandes tensões em função de uma visão misógina amplamente partilhada por numerosos homens, inclusive aqueles pertencentes às classes trabalhadoras. De um ponto de vista político, sabemos por exemplo da resistência dos meios operários europeus do século XIX, inclusive politizados (de todas as tendências) ao trabalho assalariado, à sindicalização e até mesmo à politização das mulheres (a política sendo pensada, essencialmente, como um “assunto de homens"). Portanto, se as classes dominantes acionavam de fato um racismo de classe contra as classes trabalhadoras, isto não impedia de modo algum a constituição de um "fronte de classes" entre homens para manter (e, às vezes, até mesmo estender) os privilégios patriarcais dentro de "fraternidades masculinas" que se (re)constituíam em muitas instituições não-mistas (escola, exército...) e em espaços de sociabilidade (rua, café, clube de esporte, bordel...) totalmente ou parcialmente interclassistas ${ }^{13}$. Este fato levou a militante feminista e revolucionária Flora Tristan a apontar para a uma simples evidência, ainda atual nos dias de hoje em muitos contextos: "O mais oprimido dos homens pode oprimir um ser, que é sua mulher. Ela é o proletário do proletário" ${ }^{14}$. Este "direito de proprietário", gravado na ordem do gênero, cuja origem é muito remota ${ }^{15}$, afetou forte e duradouramente as mulheres, como bem demonstram, nas teorias feministas, as reflexões desenvolvidas sobre o continuum de violências ${ }^{16}$ que

\footnotetext{
${ }^{13} \mathrm{O}$ interclassismo não implica, evidentemente, na ausência de hierarquizações entre homens ou grupos de homens, nem produção de poder(es), de discriminação(ões) e de violência(s).

14 Importante destacar que, dentro das classes trabalhadoras politizadas, homens foram de fato aliados objetivos e efetivos das mulheres. Destacamos também que houve, por exemplo, nos meios anarquistas e libertários, uma vontade muito clara de preconizar uniões livres nãoreprodutivas (marcadas por práticas neomalthusianas de controle de natalidade que podiam tomar a forma, no caso das mulheres, de abortos clandestinos e, nos homens, de autoesterilização) que se opunham ao "ideal” da família patriarcal-capitalista que representava a "célula básica" de uma sociedade, "sadia", "moral” et "industriosa", organizada em torno da ideia de uma filiação legítima à qual podia-se transmitir, com toda segurança, o capital acumulado uma vez que tinha-se previamente assegurado o controle do ventre das mulheres "honestas"... Nestes meios, recusava-se então a família burguesa e sua obsessão pela filiação legítima (que se baseava na condenação inafiançável das mães solteiras e de seus "bastardos", rejeitados em uma sub-humanidade fortemente estigmatizada).

15 Podemos encontrá-lo, pelo menos desde de a Antiguidade, no "direto do possuidor" do qual o "direito do proprietário" é herdeiro nas sociedades patriarcal-capitalistas, tanto dentro das sociedades de escravos quanto nas escravagistas.

${ }^{16} \mathrm{O}$ feminicídio pode ser entendido num sentido expandido como uma série de atos antimulher que inclui, citando apenas alguns, o adestramento à feminilidade (se possível, para assegurar submissão e passividade) e a inferiorização sistêmica do feminino que pressupõe a sua subjugação enquanto "segundo sexo"; o tratamento diferenciado nas línguas e linguagens e portanto na escola (isso, quando as meninas têm o direito a frequentá-la) mas também nos
} 
Teoria(s) feminista(s) e história(s) do tempo presente: interseccionalidade, subalternidade e decolonialidade

Christelle Taraud

constituem o crime de feminicídio (TARAUD, 2022). Um sistema de terror individual e coletivo, baseado na submissão, na subjugação e na domesticação das mulheres, tal como mostraram Jane Caputi e Diana E. H. Russell (CAPUTI; RUSSEL, 1990), assim como Rosa-Linda Fregoso e Cynthia Bejarano (FREGOSO; BEJARANO, 2010), que encarna a mais antiga guerra da humanidade, aquela que os homens fizeram, desde sempre, contra as mulheres (SOLNIT, 2014; SEGATO, 2016). Uma guerra que conheceu vários pontos culminantes: das caças às bruxas da época moderna -que correspondem também, não esqueçamos, ao primeiro momento de acúmulo de capital, como apontado acertadamente por Silvia Federici no seu livro pioneiro, Caliban e a bruxa (FEDERICI, 2014, 2021), aos feminicídios de massa atuais, que afetam vários continentes, e que Ciudad Juarez exemplifica de modo paradigmático...

Em resposta a esta "internacional patriarcal” fundada nas relações de gênero sistemicamente desiguais ${ }^{17}$, que, como bem lembrado por Rita Laura Segato, é "a mais arcaica e persistente das estruturas políticas da humanidade" (SEGATO, 2018, p. 199), as feministas, em primeiro lugar, as teorias feministas depois, prepararam a réplica por meio da constituição de espaços de ação/ões, de reflexão/ões, de produção/ões política(s) e científica(s) ${ }^{18}$ tomando lugar na

sistemas políticos (onde as mulheres, quando têm direito ao voto, são geralmente subrepresentadas) e religiosos (cosmogonias, monoteísmos...); as discriminações econômicas essencializadas, especialmente dentro do capitalismo patriarcal predador; o assédio sexual nos espaços públicos (rua, transportes coletivos, campi universitários, ambientes de trabalho); as humilhações, os insultos e as agressões físicas (dentro e fora do espaço conjugal/familiar); as mutilações corporais e sexuais, os casamentos precoces e/ou forçados, as maternidades compulsórias e, ao inverso, os abortos e as esterilizações forçadas, os feticídios ou os infanticídios ao feminino, as piadas sexistas e as propagandas machistas; a pornografia hétero; a coerção à heterossexualidade e à lesbofobia; a prostituição forçada e a putafobia; a escravidão sexual sob todas as suas formas, os abusos sexuais (inclusive a pedofilia e o incesto que atingem ainda em maioria as meninas); os estupros (conjugais, por familiares ou estranhos, corretivos, de guerra, genocidários...) e claro, in fine, os próprios assassinatos...

17 Tomemos, por exemplo, o caso francês. A Revolução Francesa (1789-1799) - que viu surgir a Primeira República em 21 de setembro de 1792 - foi feita em grande parte contra as mulheres que foram excluídas da cidadania ativa logo em 1789. Aliás, esta situação antimulher levou, durante o Primeiro Império (1804-1815), à promulgação no âmbito do Código Napoleônico (21 de março de 1804) de uma legislação misógina presente com todas as letras no artigo 223: "A mulher deve obediência ao seu marido, o marido proteção à sua mulher". A partir deste momento, as mulheres (e particularmente as esposas e as viúvas com filhos) se tornam "menores para o resto da vida" (agrupadas na mesma categoria que as crianças e os loucos), submetidas ao espaço doméstico e à procriação (o "ofício da mulher").

18 Observemos que alguns destes espaços eram não-mistos. Além do mais, é interessante especificar que a não-mixidade gera muitos problemas e é alvo de muitas críticas quando provém de mulheres apresentadas como "separatistas" e/ou "comunitaristas", inclusive pobres e/ou racializadas, enquanto que parece tão trivialmente "natural" para os homens quando se 
"raiz do ma(l)/cho" - o patriarcado - no cerne das questões epistemológicas, teóricas e políticas. Já em 1977, a socióloga e feminista materialista Christine Delphy definia o principal inimigo das mulheres (e por consequência de todos/as os/as oprimidos/as) como sendo o patriarcado (DELPHY, 1977, 2009)19. Hoje ainda, e apesar de avanços concretos conseguidos após árdua luta, porém frágeis e muitas vezes ameaçados (me vem em mente o exemplo do direito ao aborto, inclusive na Europa), parece claro, como apontado ainda por Rita Laura Segato, que "Todas as formas de supremacia, econômicas, políticas, coloniais e raciais, são de fato réplicas da ordem patriarcal. É por este motivo que nos encontramos, ainda, no tempo estagnado da pré-história patriarcal da humanidade" (SEGATO 2018, p. 199).

\section{Decolonialidade(s) mundializada(s)}

Quando publica, em 1988, “As subalternas podem falar?”, Gayatri Chakravorty Spivak não denuncia apenas a dominação totalizante (observaremos aqui a ligação clara com as teorias feministas de Christine Delphy e de Monique Wittig) do pensamento ocidental que ora chamamos de eurocentrismo ou ocidentalocentrismo, mas desmonta-demonstra, na encruzilhada dos Gender Studies, dos Subaltern Studies e dos Post-colonial Studies, que é impossível analisar a história da opressão das mulheres sem levar em conta as lógicas racistas, imperialistas - e capitalistas desde o advento da "modernidade" ocidental - que a moldaram (SPIVAK, 1988). Para tanto, e na extensão dos Women Studies - especialmente do começo da her history - não somente as narrativas dos/as dominados/as devem em si ser levadas em conta (o que leva a não trabalhar sobre mas com os indivíduos, os grupos e/ou as sociedades envolvidas) mas, para além disso, as subalternas elas-mesmas - em especial quando estas subalternas são mulheres que nascem, crescem, vivem, morrem em sociedades fortemente patriarcais e heteronormativas, misóginas, homofóbicas, transfóbicas e putafóbicas (ATTIA; OBOLO; TARAUD, 2020) - devem ser consideradas

\footnotetext{
aplica a uma sociabilidade do entre-si.

19 Publicado pela primeira vez em inglês com o título The Main Enemy [Londres, W.R.R.C.P., 1977], foi reeditado depois em francês. Christine Delphy, L'ennemi principal (Tome 1): économie politique du patriarcat, Paris, Syllepse, 2009 [1998].
} 
enquanto sujeitos ativos et pensantes de seus próprios atos e de suas próprias histórias (individuais e coletivas) e, portanto, produtores/oras de suas próprias competências, saberes e narrativas.

O objetivo desta iniciativa não é apenas pôr em questão/ões, em vez de pôr em xeque (já que não se trata nem de negação da importância histórica, nem de "revanche pós-colonial" que significaria uma acusação total e definitiva), o pensamento europeu em sua dimensão "universal" (que, embora tenha sido um "pensamento mundo", não é e nunca foi um pensamento para todo mundo) e seu caráter obrigatório (como no questionamento, por parte de Monique Wittig, da necessidade do contrato heterossexual), mas de reconhecer a pluralidade da(s) existência(s)/experiência(s) e das modalidades práticas, teóricas e simbólicas de sua(s) múltipla(s) expressão/ões através de pluri-interpretação/ões / reflexão/ões pensamentos de modo horizontal ("rente ao chão", poderíamos dizer) e não hierárquico. Aqui, surgiria uma perspectiva multifocal de segmentos policromáticos, de rastros difusos e de narrativas fragmentárias, fazendo corpounidade não por categorização-hierarquização fixista, mas por justaposiçãoconvivência lábil.

Deste modo, criticar a imposição, pelo viés da subalternidade e da (de)colonialidade, do caráter obrigatório da "modernidade ocidental" sem no entanto negar sua utilidade entre outras possíveis, é ao mesmo tempo trazer uma leitura renovada da história da Europa em si (se a guerra de classes existiu, sem falar da dominação sistemática das mulheres pelos homens nos regimes patriarcais europeus, é justamente porque, antes de tudo, a Europa construiu, dentro de si mesma, os seus próprios Outros), mas também da história do mundo (fazendo a ligação entre a construção endógena e, em seguida, exógena da Alteridade especialmente graças à criação, na virada dos séculos XVIII e XIX, do "racismo científico"). Mesmo sendo a proposta renovadora, cabe menos "provincializar" a Europa e/ou o Ocidente - como propõe, por exemplo, Dipes Chakrabarty (CHAKRABARTY, 2000, 2020) - que (re)colocá-la no seu devido lugar. Fazer isto seria pôr em prática(s) uma revolução radical em todos os níveis, materiais e epistemológicos, já que isso aniquilaria a ideia de que tudo o que não 
vem dela - ou seja, o "centro" - seria necessariamente proveniente de suas “margens”, então “subalterno”, justamente.

É com este pensamento que é preciso romper de modo definitivo, uma vez que este é ao mesmo tempo portador de infantilizações paternalistas e/ou racistas inaceitáveis (como aquelas a respeito, por exemplo, dos "povos ingênuos e infantis", espécie de replicação do mito rousseauniano do "bom selvagem", refutando a "modernidade" ocidental enquanto "sentido da história"), sendo ao mesmo tempo herdeiro de uma brutalização geral dos indivíduos, dos grupos, das sociedades e dos Estados que constituem nosso mundo comum (desta forma, seria particularmente interessante discutir o continuum de violências intraeuropeias que representam as caças às bruxas/as guerras de classes e suas representações sangrentas/e a SHOAH como expressões locais de matrizes genocidas racial-coloniais globais experimentadas em outros continentes a partir do século XV e reintroduzidas na própria Europa); e, por fim, do próprio planeta (tal como denunciam regularmente os/as representantes dos povos originários e as primeiras nações e/ou as ecofeministas desde pelo menos os anos 1970, uma vez que várias são as relações entre eles/elas e algumas de suas ações são comuns).

\section{Conclusão/ões provisória(s)}

Desta forma, as teorias feministas permitem apreender o próprio passado dentro do presente das nossas sociedades, o que me leva a concluir (sem concluir) em três etapas distintas e conexas.

Nos tempos mais antigos (que sem dúvida levam de volta à pré-história da humanidade), aqueles do nascimento dos regimes patriarcais, é a mulher que constituiu a colônia original, sendo que ela encarnou, em si, um território a arrasar, a conquistar e, por fim, a colonizar. Graças a ela, o homem pôde "frutificar e multiplicar": ou seja, dar a si mesmo, usando o corpo das mulheres como primeiro "campo de batalha" mas também como primeira "colônia de povoamento", os meios de sua futura expansão exterior. Logo, colonizar as mulheres (tanto como espaço quanto corpo) é quase, em toda parte, a primeira etapa dos anseios expansionistas dos grupos e das sociedades organizadas sobre 
princípios patriarcais. Deste modo, a "mulher-colônia" está na origem dos processos coloniais e no centro de todas as guerras que foram travadas para realizá-los: a apropriação das mulheres - Outras e dos Outros - tendo precedido e se perpetuado até hoje, a colonização efetiva das terras, desde os períodos antigos até as primeiras colonizações europeias dos "novos mundos" - que são irremediavelmente associadas tanto ao tráfico do atlântico e à massificação da escravidão quanto à destruição e/ou miserização dos povos originários e das primeiras nações na maior parte do planeta.

Num segundo momento, aquele do primeiro e segundo acúmulos de capital, as colonizações europeias foram também fortemente conectadas ao racismo de classe e ao racismo biológico, especialmente no século XIX, visto que elas se tornam "laboratórios do social" com o intuito de transformar "proletários em proprietários" em terras “indígenas" confiscadas e/ou espoliadas, encurralando então os povos colonizados em "reservas-morredouros" (nas quais os raros sobreviventes destas mesmas populações se encontram ainda hoje "ajuntados"), dentro de "colônias de exploração ou de povoamento" mortíferas para eles; mas também de imensas prisões permitindo, à Europa, se livrar de seus indesejáveis: pobres, criminosos, órfãos, prostitutas, oponentes políticos. Assim, como bem demonstrado pela historiadora e antropóloga Ann Laura Stoler (STOLER, 1985,2013), as colônias se tornaram os "espaços concentracionários" tanto dos ilegalismos proletários (como aconteceu inicialmente para os britânicos na Austrália) quanto das "raças inferiores" fadadas à assimilaçãoaculturação ou à morte (real e/ou simbólica, material e/ou epistêmica ${ }^{20}$ ) dentro de economia(s) de saque(s) e de devastação/ões.

No terceiro momento da mundialização, sendo então o nosso, num mundo onde a descolonização se deu de maneira muito imperfeita (especialmente a das ciências e das consciências, as duas coisas sendo simbioticamente ligadas a meu ver), onde a "violência pandêmica contra as mulheres" ${ }^{21}$ se espalha por toda parte como uma praga, e onde a guerra mundial travada contra os pobres (tanto dentro

\footnotetext{
${ }^{20}$ Como mostra o debate, muito intenso na Europa, a respeito da espoliação cultural do continente africano durante as colonizações contemporâneas dos séculos XIX e XX e a questão, muito atual, da devolução das obras...

${ }^{21}$ Para retomar uma expressão de Rosa-Linda Frogoso.
} 
como fora dos países ditos ricos e/ou industrializados) é visível em todos os lugares, é agora mesmo que a sobrevivência do próprio planeta está em jogo. Este “momento" que foi tomado, desde os anos 1970, pelas ecofeministas especialmente Françoise d'Eaubonne (D’EAUBONNE, 1978, 2018), Vandana Shiva (SHIVA, 1983, 1999) e Starhawk (STARHAWK, 1982,2015)... - fazendo a relação entre os sistemas de dominação patriarcal-raciais que buscam se apropriar, explorar e domesticar as mulheres e/ou pobres e/ou racializadas e as lógicas de espoliaçãosobre-exploração da natureza pela predação capitalista/imperialista (provocando a perturbação climática, a devastação dos ecossistemas e o sufocamento do planeta), tem por objetivo repensar as relações entre os gêneros ao mesmo tempo que as relações entre os humanos e a natureza. É neste ponto exato que as teorias ecofeministas convergem com as ideias radicais de algumas pensadoras da Queer Theory - do manifesto cyborg da teórica e ecofeminista Donna Haraway (HARAWAY, 1985, 2009) à performatividade do gênero da filósofa feminista e queer Judith Butler (BUTLER, 1990, 2006) - dentro de uma reflexão a respeito do futuro de uma pós-humanidade a ser construída.

Uma pós-humanidade que teria finalmente saído de sua pré-história patriarcal, capitalista e racial (re)construindo um mundo consertado e apaziguado, inclusivo e igualitário... ou melhor dizendo, humano...

\section{Referências}

ATTIA, Kader; OBOLO, Pascale; TARAUD, Christelle (dir.). La prostitution coloniale et post-coloniale. Paris: La Découverte, 2020.

BUTLER, Judith. Gender trouble: feminism and the subversion of identity. New York: Routledge, 2006.

CAPUTI, Jane; RUSSELL, Diana E. H. Femicide: Sexist Terrorism against Women. In: RADFORD, Jill; RUSSELL, Diana E.H. (eds.). Femicide: the politics of women killing. New York: Twayne Publishers, 1990. p. 13-21.

CHAKRABARTY, Dipesh. Provincialiser l'Europe, la pensée postcoloniale et la différence historique. Paris: Editions Amsterdam, 2020. 
CRENSHAW, Kimberlé. Demarginalizing the intersection of race and sex: a black feminist critique of antidiscrimination doctrine, feminist theory and antiracist politics. University of Chicago Legal Forum, [s.l.], v. 1989, Issue 1, Article 8, 1989. Disponible en: http://chicagounbound.uchicago.edu/uclf/vol1989/iss1/8.

DELPHY, Christine. L'ennemi principal (tome 1): économie politique du patriarcat. Paris: Syllepse, 2009.

D'EAUBONNE, Françoise. Écologie, féminisme: révolution ou mutation? Paris: Libre et Solidaire Éditeur, 2018.

FEDERICI, Silvia. Caliban et la sorcière: femmes, corps et accumulation primitive. Paris: Entremonde, 2014.

FEDERICI, Silvia. Une guerre mondiale contre les femmes: des chasses aux sorcières au féminicide. Paris: La Fabrique, 2021.

FREGOSO, Rosa-Linda; BEJARANO, Cynthia. Terrorizing women: feminicide in the Americas. Durham: Duke University Press, 2010.

HARAWAY, Donna. Manifesto for cyborgs: science, technology, and socialist feminism in the 1980s. Socialist Review, [s.l.], n. 80, p.65-108, 1985.

HARAWAY, Donna. Des singes, des cyborgs et des femmes: la réinvention de la nature. Paris : Éditions Jacqueline Chambon, 2009.

KATZ, Jonathan Ned. The Invention of Heterosexuality. Socialist Review, n. 20, 1990.

KATZ, Jonathan Ned. The invention of heterosexuality. Dutton: [s.n.], 1995.

MIES, Maria; SHIVA, Vandana. L'écoféminisme, Paris: L'Harmattan, 1999.

$\mathrm{RICH}$, Adrienne. Compulsory heterosexuality and lesbian existence. Signs, v. 5, n. 4, p. 631-660, été 1980.

ROSSITER, Margaret W. L'effet Mathilda en sciences. Les cahiers du CEDREF. Centre d'enseignement, d'études et de recherches pour les études féministes, n. 11, p. 21-39, 2003.

SEGATO, Rita Laura. La guerra contra las mujeres. Madrid: Traficantes de Sueños, 2016.

SEGATO, Rita Laura. Manifesto in four themes. Critical times, v. 1, issue 1, p. 198211, 2018.

SOLNIT, Rebecca. The longest war. In: SOLNIT, Rebecca. Men explain things to me? Chicago: Haymarket Books, 2014. 
SPIVAK, Gayatri Chakravorty. Can subaltern speak? In: NELSON, Cary; GROSSBERG, Lawrence (eds.). Marxism and the interprétation of culture. Champaign: University of Illinois Press, 1988. p. 271-313.

STARHAWK. Rêver l'obscur: femmes, magie et politique. Paris: Cambourakis, 2015.

STOLER, Ann Laura. Capitalism and confrontation in sumatra's plantation belt, 1870-1979. Ann Arbor: University of Michigan Press, 1985.

STOLER, Ann Laura. Imperial debris: on ruin and ruination. Durham: Duke University Press, 2013.

TARAUD, Christelle (dir.). Les féminismes en questions: eléments pour une cartographie. Entretiens avec Christine Bard, Marie Hélène Bourcier, Christine Delphy, Eric Fassin, Françoise Gaspard, Nacira Guénif Souilamas, Marcela lacub. Paris: Amsterdam, 2005.

TARAUD, Christelle. Les bagnes de l'Empire au féminin: où comment déporter les opposantes politiques de la métropole dans les colonies françaises au XIXe siècle. In: MORELLI, Anne (dir.). Femmes exilées politiques: sextant. Bruxelles: Presses de l’Université Libre de Bruxelles, 2009. n. 26. p. 17-25.

TARAUD, Christelle. (dir.). Féminicides: une histoire mondiale. Paris: La Découverte, 2022. (à paraître donc).

TIN, Louis Georges. Comment peut-on être hétérosexuel? In: DESCHAMPS, Catherine; GAISSAD, Laurent; TARAUD, Christelle. Hétéros: discours, lieux, pratiques. Paris: EPEL, 2009. p. 17-27.

WITTIG, Monique. La pensée Straight. Questions Féministes, n. 7, p. 45-53, février 1980. Disponible en: http://www.jstor.org/stable/40619186. 